Research article

\title{
Activated leukocyte cell adhesion molecule in breast cancer: prognostic indicator
}

\author{
Judy A King 1,2,3, Solomon F Ofori-Acquah'3,4, Troy Stevens ${ }^{2,3}$, Abu-Bakr Al-Mehdi2,3, \\ Oystein Fodstad ${ }^{5}$ and Wen G Jiang 6
}

\author{
1Department of Pathology, University of South Alabama, Mobile, Alabama, USA \\ 2Department of Pharmacology, University of South Alabama, Mobile, Alabama, USA \\ ${ }^{3}$ Center for Lung Biology, University of South Alabama, Mobile, Alabama, USA \\ ${ }^{4}$ Department of Cell Biology and Neuroscience, University of South Alabama, Mobile, Alabama, USA \\ ${ }^{5}$ Cancer Research Institute, University of South Alabama, Mobile, Alabama, USA \\ ${ }^{6}$ Department of Surgery, University of Wales College of Medicine, Cardiff, UK
}

Corresponding author: Judy A King, jking@usouthal.edu

Received: 23 Feb 2004 Revisions requested: 22 Mar 2004 Revisions received: 7 May 2004 Accepted: 17 May 2004 Published: 28 Jun 2004

Breast Cancer Res 2004, 6:R478-R487 (DOI 10.1186/bcr815)

(c) 2004 King et al.; licensee BioMed Central Ltd. This is an Open Access article: verbatim copying and redistribution of this article are permitted in all media for any purpose, provided this notice is preserved along with the article's original URL.

\begin{abstract}
Introduction Activated leukocyte cell adhesion molecule (ALCAM) (CD166) is an immunoglobulin molecule that has been implicated in cell migration. The present study examined the expression of ALCAM in human breast cancer and assessed its prognostic value.
\end{abstract}

Methods The immunohistochemical distribution and location of ALCAM was assessed in normal breast tissue and carcinoma. The levels of ALCAM transcripts in frozen tissue (normal breast, $n=32$; breast cancer, $n=120$ ) were determined using realtime quantitative PCR. The results were then analyzed in relation to clinical data including the tumor type, the grade, the nodal involvement, distant metastases, the tumor, node, metastasis (TNM) stage, the Nottingham Prognostic Index (NPI), and survival over a 6-year follow-up period.

Results Immunohistochemical staining on tissue sections in ducts/acini in normal breast and in breast carcinoma was ALCAM-positive. Differences in the number of ALCAM transcripts were found in different types of breast cancer. The level of ALCAM transcripts was lower $(P=0.05)$ in tumors from patients who had metastases to regional lymph nodes compared with those patients without, in higher grade tumors compared with Grade 1 tumors $(P<0.01)$, and in TNM Stage 3 tumors compared with TNM Stage 1 tumors $(P<0.01)$. Tumors from patients with poor prognosis (with NPI $>5.4$ ) had significantly lower levels $(P=0.014)$ of ALCAM transcripts compared with patients with good prognosis (with NPI <3.4), and tumors from patients with local recurrence had significantly lower levels than those patients without local recurrence or metastases $(P=0.04)$. Notably, tumors from patients who died of breast cancer had significantly lower levels of ALCAM transcripts $(P=0.0041)$ than those with primary tumors but no metastatic disease or local recurrence. Patients with low levels of ALCAM transcripts had significantly $(P=0.009)$ more incidents (metastasis, recurrence, death) compared with patients with primary breast tumors with high levels of ALCAM transcripts.

Conclusions In the present panel of breast cancer specimens, decreased levels of ALCAM correlated with the nodal involvement, the grade, the TNM stage, the NPI, and the clinical outcome (local recurrence and death). The data suggest that decreased ALCAM expression is of clinical significance in breast cancer, and that reduced expression indicates a more aggressive phenotype and poor prognosis.

Keywords: ALCAM, breast cancer, metastasis, prognosis

\section{Introduction}

The breast is the most frequent site of cancer in women (excluding skin cancer) and ranks second to lung cancer in the number of deaths in women [1]. It is generally accepted that important prognostic factors in breast cancer include the size of the primary breast tumor (included in tumor, node, metastasis [TNM] staging), the histologic type, the histologic grade, the presence or absence of regional/axillary lymph node metastases (included in the TNM staging system), the presence or absence of distant metastases 
(included in the TNM staging system), and the presence or absence of estrogen receptors and progesterone receptors (see review in[2]). Research for other prognostic factors is ongoing with the goal to predict aggressiveness and response to treatment.

Activated leukocyte cell adhesion molecule (ALCAM) is a glycoprotein of the immunoglobulin superfamily. ALCAM has been identified in multiple species and has different names depending on the species and laboratory that described it: chicken neural adhesion molecule BEN/SC1/DM-GRASP [3-5], rat KG-CAM [6], fish neurolin [7], human melanoma metastasis clone D (MEMD) [8], mouse/ human CD166 [9,10], and rat HB2 [11,12]. ALCAM has five extracellular immunoglobulin domains (two $\mathrm{NH}_{2}$-terminal, membrane-distal variable- [V]-type folds and three membrane-proximal constant- [C2]-type immunoglobulin folds), a transmembrane region, and a short cytoplasmic tail [13]. It is involved in both homotypic/homophilic adhesion and heterotypic/heterophilic (to CD6) adhesion [13,14]. ALCAM has been shown to be involved in capillary tube formation [15] and in vessel invasion into cartilage in vitro [16].

ALCAM has been studied in two tumor types malignant melanoma [17] and prostate carcinoma [18]. In 1998 Degen and colleagues isolated MEMD in human melanoma cell lines and found a correlation with aggregation and enhanced metastatic ability [8]. MEMD/ALCAM was involved in melanoma cell-melanoma cell interactions, suggesting a homophilic interaction between tumor cells [8]. van Kempen and colleagues [17] studied human melanocytic lesions and found that ALCAM expression correlated with melanoma progression. Approximately one-half of melanoma metastases had ALCAM positivity. The authors concluded that ALCAM plays a role in melanoma tumor progression. Using chip-based RNA transcript analysis, Kristiansen and colleagues [18] studied ALCAM in prostate cancer and found that ALCAM expression is often altered in prostate carcinoma. They theorized that it may be involved in progression of disease.

Only one previous work has mentioned ALCAM in breast carcinoma. Degen and colleagues [8] performed northern blot analysis of MEMD mRNA and found expression in the MCF-7 mammary carcinoma cell line. Our laboratory is evaluating the role of ALCAM in breast carcinoma. Studies have shown that ALCAM is present in breast cancer cell lines and resected breast tumors [19]. Antibody to ALCAM decreases proliferation of breast cancer cells and decreases the adhesion of breast cancer cells to each other [19]. Proliferation and adhesion are both features that are critical to tumor cell growth and metastases. With the data on the other tumor types and data from our laboratory, we decided to evaluate ALCAM expression in breast carci- noma using tissue from patients who have been followed for 6 years and have been studied extensively [20-25] to determine whether ALCAM expression is a prognostic indicator. Our results suggest that decreased ALCAM expression is of clinical significance in breast cancer.

\section{Materials and methods Materials}

The RNA extraction kit and the RT kit were obtained from AbGene Ltd (Surrey, UK). PCR primers were designed using Beacon Designer (Palo Alto, CA, USA) and synthesized by Invitrogen Ltd (Paisley, UK). Molecular biologygrade agarose and the DNA ladder were from Invitrogen (Carlsbad, CA, USA). The master mix for routine PCR and quantitative PCR (Qabsolute) were from AbGene Ltd. Mouse monoclonal antibody ALCAM/CD166 (for immunohistochemistry) was obtained from Novocastra Laboratories (Newcastle upon Tyne, UK). Peroxidase conjugated anti-mouse antibodies were from Sigma (Poole, UK) and a biotin universal kit was from Dako Ltd (Carpinteria, CA, USA).

\section{Sample collection}

Primary breast cancer tissues $(n=120)$ and non-neoplastic mammary tissue (from the same mastectomy specimens) ( $n=32)$ were collected immediately after surgery (mastectomy) and stored in the deep freezer $\left(-70^{\circ} \mathrm{C}\right)$ until use (collected with approval of local ethical committees in Cardiff and London). Details of histology were obtained from pathology reports (Table 1 ). Patients were routinely followed clinically after surgery and their details stored in a database. The median follow-up period was 72 months. The presence of tumor cells in the tissues were independently assessed by a specialist pathologist using $\mathrm{H}$ \& $\mathrm{E}$ stained frozen sections. Where normal non-neoplastic mammary tissues were used, no tumor cells were found in the sections.

Additional formalin-fixed, paraffin-embedded archival tissue with normal breast (from mastectomy specimens with cancer elsewhere and from breast reduction surgeries) and with breast cancer were used for immunohistochemical staining. (Institutional Review Board approval was obtained for tissue obtained in the United States.)

\section{Tissue processing, RNA extraction, and cDNA synthesis}

Frozen sections of tissue were cut at a thickness of 5-10 $\mu \mathrm{m}$ and were kept for immunohistochemistry and routine histology. Other 15-20 $\mu \mathrm{m}$ sections were mixed and homogenized using a hand-held homogenizer, in ice-cold RNA extraction solution. The concentration of RNA was determined using an UV spectrophotometer. Reverse transcription was carried out using a RT kit with an anchored oligo dT primer supplied by AbGene, using $1 \mu \mathrm{g}$ total RNA $a$ in 96-well plate. The quality of cDNA was verified using $\beta$ - 
Table 1

\begin{tabular}{|c|c|}
\hline Characteristic & $n$ \\
\hline \multicolumn{2}{|l|}{ Node status } \\
\hline Node-negative & 65 \\
\hline Node-positive & 55 \\
\hline \multicolumn{2}{|l|}{ Grade } \\
\hline Grade 1 & 23 \\
\hline Grade 2 & 41 \\
\hline Grade 3 & 56 \\
\hline \multicolumn{2}{|l|}{ Histology } \\
\hline Ductal & 88 \\
\hline Lobular & 14 \\
\hline \multicolumn{2}{|l|}{ Other } \\
\hline Medullary & 2 \\
\hline Tubular & 2 \\
\hline Mucinous & 4 \\
\hline \multicolumn{2}{|c|}{ Tumor, node, metastasis (TNM) stage } \\
\hline TNM Stage 1 & 69 \\
\hline TNM Stage 2 & 40 \\
\hline TNM Stage 3 & 7 \\
\hline TNM Stage 4 & 4 \\
\hline \multicolumn{2}{|l|}{ Clinical outcome } \\
\hline Disease free & 87 \\
\hline With metastasis & 6 \\
\hline With local recurrence & 5 \\
\hline Died of breast cancer & 16 \\
\hline Died of unrelated disease & 6 \\
\hline
\end{tabular}

actin primers (5'-caggaggttgaaggactaaa-3' and 5 '-gggatcagttttctttgtca-3').

\section{Quantitative analysis of ALCAM}

The level of ALCAM transcripts from the earlier prepared cDNA was determined using a real-time quantitative PCR, based on the Amplifluor ${ }^{\mathrm{TM}}$ technology [26], modified from a method previously reported $[22,27]$. Briefly, pairs of PCR primers were similarly designed using the Beacon Designer software (version 2) (5'-caggaggttgaaggactaaa-3' and 5'gggatcagttttcttgtca- $\left.3^{\prime}\right)$, but to one of the primers an additional sequence, known as the $Z$ sequence $(5$ '-actgaacctgaccgtaca-3'), which is complementary to the universal $Z$ probe [26] (Intergen Inc., Livingston, UK), was added to one of the primers (ALCAMZr). A Taqman detection kit for $\beta$-actin was purchased from Perkin-Elmer (Surrey, UK).

The reaction was carried out using the following: Hot-start Q-master mix (Abgene), 10 pmol specific forward primer, 1 pmol reverse primer that has the $Z$ sequence, $10 \mathrm{pmol}$ FAM-tagged probe (Intergen Inc.), and cDNA from approximately $50 \mathrm{ng}$ RNA $[20,21]$. The reaction was carried out using lcyclerlO ${ }^{\text {TM }}$ (Bio-Rad, Hemel Hempstead, UK), which is equipped with an optic unit that allows real-time detection of 96 reactions, using the following conditions: $94^{\circ} \mathrm{C}$ for $12 \mathrm{~min}, 50$ cycles of $94^{\circ} \mathrm{C}$ for $15 \mathrm{~s}, 55^{\circ} \mathrm{C}$ for $40 \mathrm{~s}$, and $72^{\circ} \mathrm{C}$ for $20 \mathrm{~s}[21,22]$. The levels of the transcripts were generated from a standard (purified plasmid with known quantity [28]) that was simultaneously amplified with the samples, and they are presented in this paper as relative levels calculated from the internal standard. The epithelial content within the tumors was taken into account by normalizing ALCAM against cytokeratin 19. The cytokeratin 19 forward and reverse primers were 5 '-caggtccgaggttactgac-3' and 5'-actgaacctgaccgtacacactttctgccagtgtgtcttc$3^{\prime}$, respectively.

\section{Immunohistochemical staining}

The procedure was similar to that previously reported, with minor modifications [22-24]. Briefly, frozen sections of breast tumor and non-neoplastic breast tissue were cut at a thickness of $6 \mu \mathrm{m}$ using a cryostat. The sections were mounted on microscope slides, air-dried and then fixed in a mixture of $50 \%$ acetone and $50 \%$ methanol. The sections were then placed in 'Optimax' (Vector Laboratories Ltd, Peterborough, UK) wash buffer for 5-10 min to rehydrate. Sections were incubated for $20 \mathrm{~min}$ in a $0.6 \%$ BSA blocking solution and probed with the primary antibody $(1: 40$ dilution ALCAM). Following extensive washings, sections were incubated for $30 \mathrm{~min}$ in the secondary biotinylated antibody (Multilink Swine anti-goat/mouse/rabbit immunoglobulin; Dako Inc.). Following washings, Avidin Biotin Complex (Vector Laboratories Ltd) was then applied to the sections, followed by extensive washings. Diaminobenzidine chromogen (Vector Laboratories Ltd) was then added to the sections, which were incubated in the dark for $5 \mathrm{~min}$. Sections were then counterstained in Gill's Haematoxylin and dehydrated in ascending grades of methanol before clearing in xylene and mounting under a coverslip.

Staining intensity was semiquantified using a method established in our laboratory [29], modified based on that reported by Fidler and colleagues [30]. Briefly, gray-scale digitized images were imported into the Optimas software (Optimas 6.0; Optimus Corp., Bothell, Washington, USA). The intensity of the cell adhesion molecules were measured in two locations from randomly chosen cells: the cytoplasmic region and the intercellular adhesion region where appropriate. Control staining (without primary antibody) 

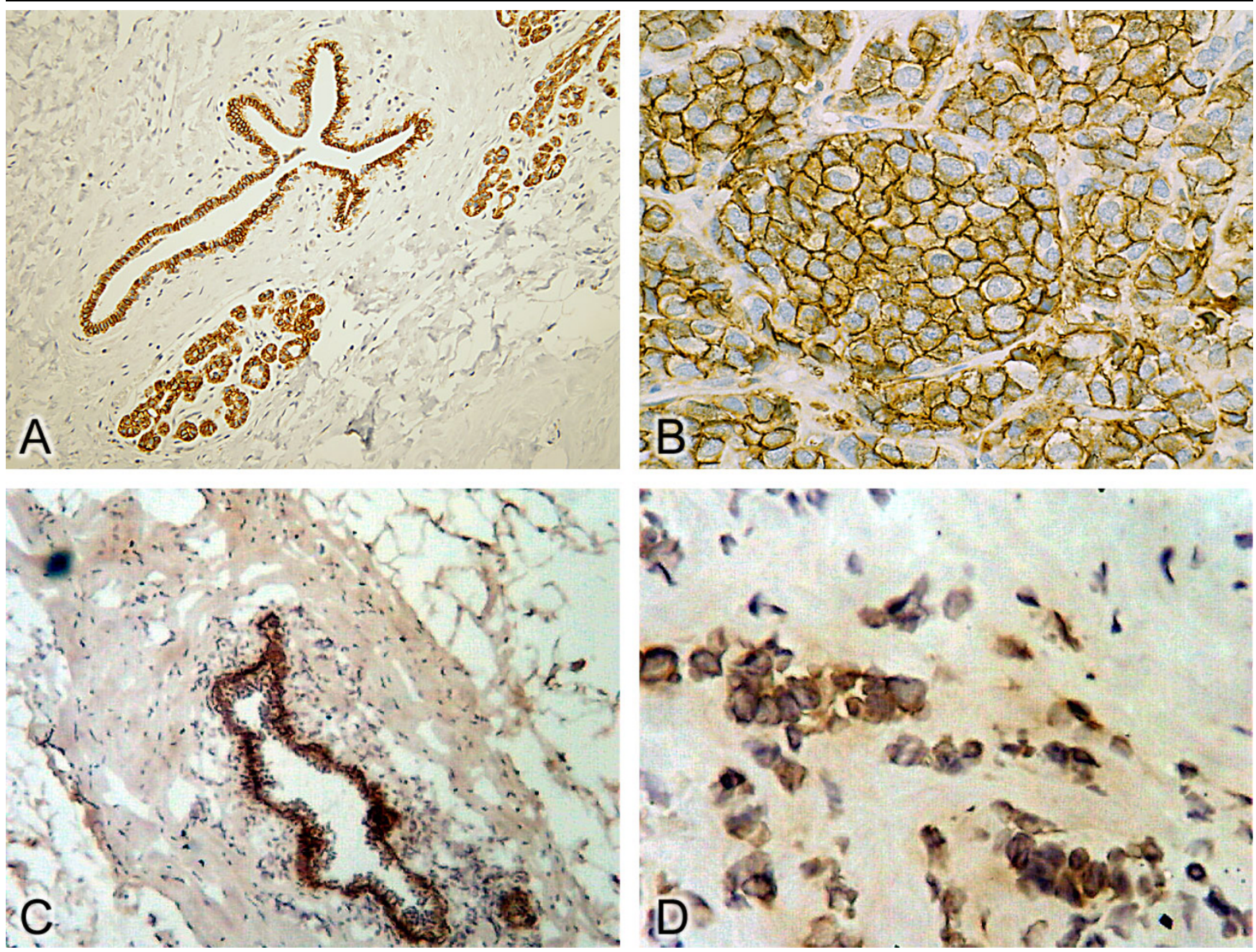

Immunohistochemical staining for activated leukocyte cell adhesion molecule (ALCAM). (a) Normal (non-neoplastic) breast tissue; formalin-fixed, paraffin-embedded tissue. Note staining in normal ducts. (b) Human breast carcinoma (infiltrating ductal carcinoma); formalin-fixed, paraffin-embedded tissue. Note strong membranous staining in breast cancer. (c) Normal (non-neoplastic) breast tissue; frozen tissue. Note staining in normal ducts. (d) Human breast carcinoma; frozen tissue. Note staining of invasive breast carcinoma.

was used for extraction of the background staining. Intensity data were exported to Excel for statistical analysis and are presented here as the mean intensity of either the cytoplasmic region or membranous staining.

Formalin-fixed, paraffin-embedded breast tissue (non-neoplastic breast and breast cancer) were sectioned (4-5 $\mu \mathrm{m}$ thick) and stained for ALCAM (1:40 dilution; Novocastra Laboratories). A high-temperature unmasking technique was utilized. Staining was performed using a Dako Autostainer.

\section{Statistical analysis}

Statistical analysis of RNA transcript data was carried out using the Mann-Whitney $U$ test and the Kruskal-Wallis test. Data for Kaplan-Meier survival curves were analyzed with Cox proportion analysis. Statistical analysis of the immunohistochemical staining was carried out using twosided two-tailed $t$ test.

\section{Results \\ ALCAM staining in normal breast and human breast cancer}

Epithelial cells from non-neoplastic mammary tissues and human breast carcinoma had strong immunohistochemical staining in both formalin-fixed tissue and frozen tissue (Fig. 1). Although not the focus of this study, the areas of carcinoma in situ seen in the sections also had positivity for ALCAM in the epithelium. A membranous pattern of staining was seen in some specimens (Fig. 1b). Analysis of the staining intensity of individual cells in frozen tissue sections have shown that the cytoplasmic staining of normal epithe- 
Figure 2

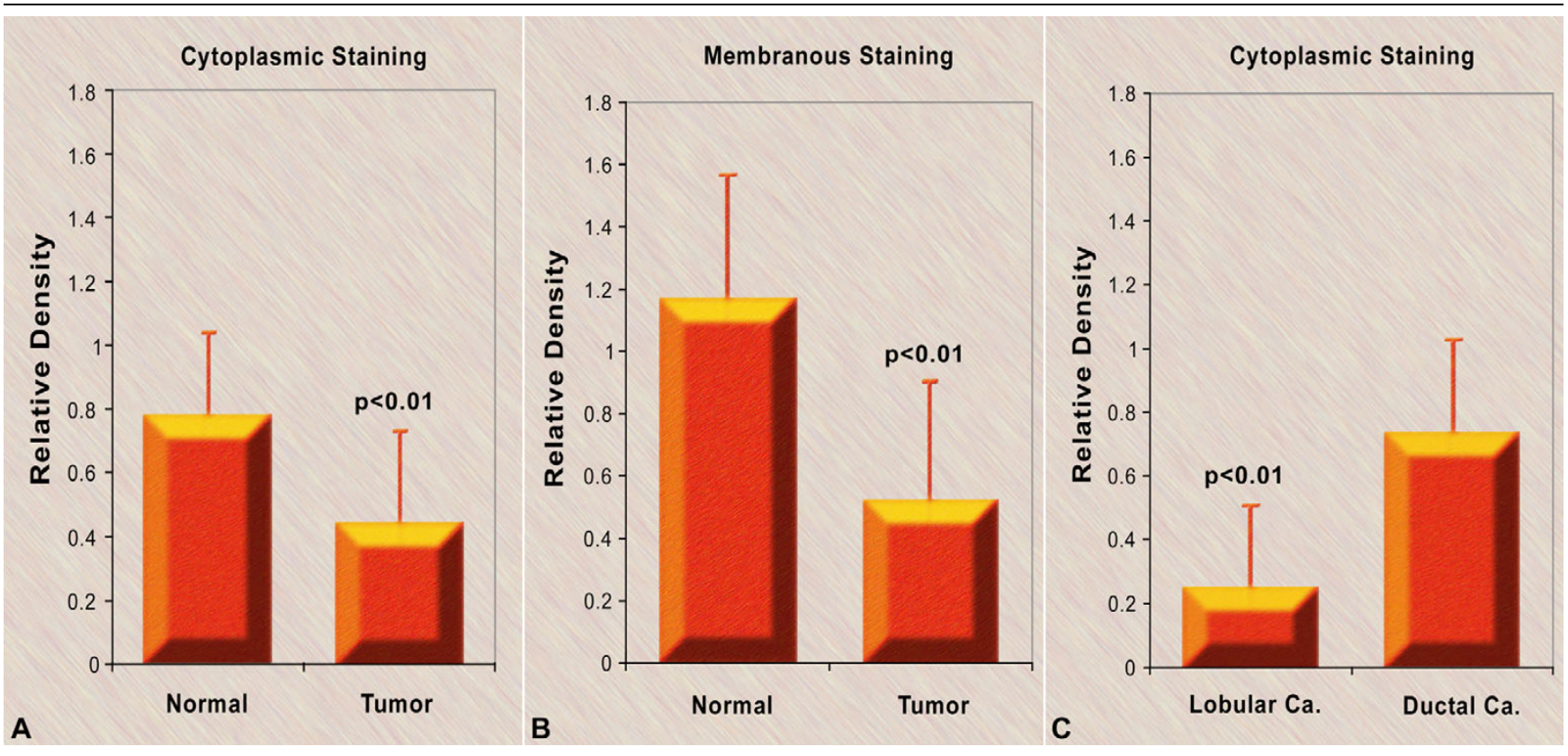

Cytoplasmic and membranous staining intensity of activated leukocyte cell adhesion molecule (ALCAM). (a) Cytoplasmic staining intensity of ALCAM of normal mammary epithelial cells and breast cancer cells (mean \pm standard deviation). (b) Membranous staining intensity of ALCAM in normal mammary epithelial cells and breast cancer cells (mean \pm standard deviation). (c) Cytoplasmic staining intensity of ALCAM in ductal and lobular tumor cells (mean \pm standard deviation). Ca, carcinoma.

lial cells was significantly stronger than that of tumor cells (Fig. 2a). Membranous staining, where visible, was generally stronger than the cytoplasmic region, and normal mammary epithelium displayed significantly higher intensity than that of breast cancer cells in frozen tissue (Fig. 2b).

\section{ALCAM transcript levels in breast cancer and normal tissues}

Figure $3 a$ shows that the number of ALCAM transcripts in breast cancer was slightly higher than in non-neoplastic breast tissue from the same mastectomy specimens $(P>$ 0.05). Discrepancies thus appear to exist between the transcript levels and protein levels. Two possibilities exist. First, the levels of ALCAM transcript and protein (as seen by staining intensity) were probably due to the difference in cellularity between tumor tissues and non-neoplastic mammary tissues. Indeed, when the transcript levels were normalized by cytokeratin 19, tumor tissues were seen to have significantly lower levels of ALCAM $(P=0.043)$ (data not shown). Second, there is the possible contribution from infiltrating immune cells in tumor tissues.

ALCAM transcripts were identified in ductal, lobular, and other (medullary, tubular, mucinous) forms of breast carcinoma (Fig. 3b). When ductal and lobular tumors were compared in their immunohistochemical staining intensity, significantly stronger cytoplasmic staining of ALCAM was seen in ductal carcinoma than in lobular tumors $(P<0.01)$ (Fig. 2c).

\section{ALCAM expression in relation to tumor grade, stage, lymph node involvement and prognosis}

Grade 2 tumors (moderately differentiated) and Grade 3 tumors (poorly differentiated) had significantly less ALCAM transcripts than Grade 1 tumors (well differentiated) $(P<$ 0.01) (Fig. 4a), and the levels were decreased in tumors from patients with TNM Stage 3 compared with TNM Stage $1(P<0.01)$ (Fig. 4b). Tumors from patients that had metastases in the lymph nodes had low levels of ALCAM transcripts $(P=0.05)$ compared with those patients without metastases in the lymph nodes (Fig. 4c). Using the Nottingham Prognostic Index (NPI), tumors from patients with $\mathrm{NPI}>5.4$ (worst prognostic group) had decreased ALCAM transcripts when compared with patients with NPI $<3.4$ (best prognostic group) $(P=0.014)$ (Fig. 4d).

Notably, the number of ALCAM transcripts were decreased in tumors from patients who had local recurrence $(P=$ 0.04 ) (Fig. 5) and were significantly decreased in tumors of patients who died from breast cancer $(P=0.0041)$. The patients were divided into those with high levels and those with low levels of ALCAM transcripts, with levels from patients who had a moderate prognostic index (NPI-2 group) as the cut-off point. The Kaplan-Meier survival curve 
Figure 3

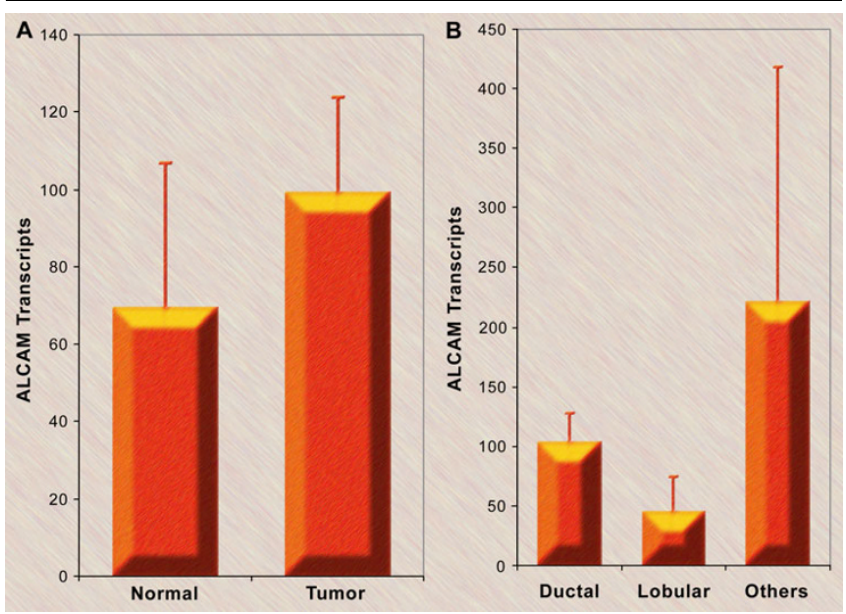

Activated leukocyte cell adhesion molecule (ALCAM) numbers in breast cancer. (a) The ALCAM transcript number in breast cancer and non-neoplastic tissue from the same mastectomy specimens (mean \pm standard deviation). (b) The ALCAM transcript number and tumor type. The 'others' category includes two cases of medullary carcinoma, two cases of tubular carcinoma, and four cases of mucinous carcinoma (mean \pm standard deviation).

(Fig. 6) of all incidents (all but disease free; includes metastasis, recurrence, and death) show a significant difference (Cox proportion analysis, $P=0.009$ ) between patients with high levels and those with low levels of ALCAM.

\section{Discussion}

This study is the first to focus on ALCAM expression and its prognostic value in breast carcinoma. Normal ductal epithelial cells in breast tissue showed positivity to ALCAM in immunohistochemical stains (Fig. 1). This positivity was also seen in invasive breast carcinoma, although the levels (both cytoplasmic and membranous) were lower than that of normal (non-neoplastic) mammary epithelium in the stained frozen tissue sections (Fig. 2). Immunohistochemical staining of breast tissues alone with the antibody used would therefore not distinguish between benign cells and malignant cells. The established pathologic criteria for carcinoma, including the architecture, nuclear pleomorphism, and mitotic counts, have to be evaluated.

The level of ALCAM transcripts appears to be higher in primary tumors compared with normal (non-neoplastic) breast tissue from the same mastectomy specimens, although it was not statistically significant (Fig. 3a). This was in contrast to the immunohistochemical staining, in that individual tumor cells stained weaker than individual normal mammary epithelial cells in the frozen tissue samples (Fig. 2a,2b). Possibilities for this discrepancy may rest with different epithelial/tumor cell content in different tumors and the possible contribution from infiltrating immune cells. Hematopoietic stem cells and activated T lymphocytes express ALCAM [31-34]. The majority of leukocytes in the formalin-fixed, paraffin-embedded breast tissue sections do not exhibit immunohistochemical staining for ALCAM. Tissue histiocytes stain with antibody to ALCAM, as do some cells in lymphoid aggregates. One could also argue that non-neoplastic breast tissue in areas without tumor in these specimens is not truly 'normal'. Ductal and acinar structures in normal breast tissue obtained from breast reduction surgeries, however, also showed strong immunohistochemical staining for ALCAM. It therefore appears that ALCAM is present normally but may have an altered expression in tumors.

Infiltrating ductal carcinoma is the most common form of invasive breast carcinoma. The transcript number was evaluated in ductal and lobular carcinomas as well as in a group of other less frequent types of breast tumors (medullary, tubular, and mucinous) (Fig. 3b). Differences in transcript numbers were seen between the groups, with lobular carcinomas generally having less ALCAM transcripts than ductal carcinomas, whereas the number of 'other' cases included was too low to make an accurate assessment. The same staining pattern of other cell adhesion molecules (namely, E-cadherin) has also been reported [35-37]. Ecadherin expression is lower in lobular breast carcinoma than in infiltrating ductal carcinoma [35]. E-cadherin is considered a tumor suppressor, with loss of E-cadherin correlating with invasion and metastases [38].

There was a statistically significant difference $(P<0.01)$ of ALCAM transcript levels between the Grade 2 tumors (moderately differentiated) and Grade 3 tumors (poorly differentiated) compared with Grade 1 tumors (well differentiated) (Fig. 4a). Higher grade tumors in general are less differentiated, more pleomorphic, and more mitotically active, and they exhibit a tendency for decreased ALCAM transcript numbers.

It is well known that the presence or absence of regional/ axillary nodal metastases is an important prognostic parameter. ALCAM transcripts were decreased in patients with metastases to regional nodes, although the numbers are not statistically significant $(P=0.05)$ (Fig. 4c).

The TNM system for classifying tumors includes evaluation of the tumor, regional lymph nodes, and distant metastases. This system includes the primary tumor size and number of lymph nodes involved in the axilla. The higher the TNM classification, the worse the patient survival rate [2]. Our study showed that primary tumors from patients with TNM Stage 3 had significantly less $(P<0.01)$ ALCAM transcripts than those with TNM Stage 1 tumors (Fig. 4b).

Another clinical parameter of prognosis is the NPI [39], which combines tumor size, lymph node stage and histo- 


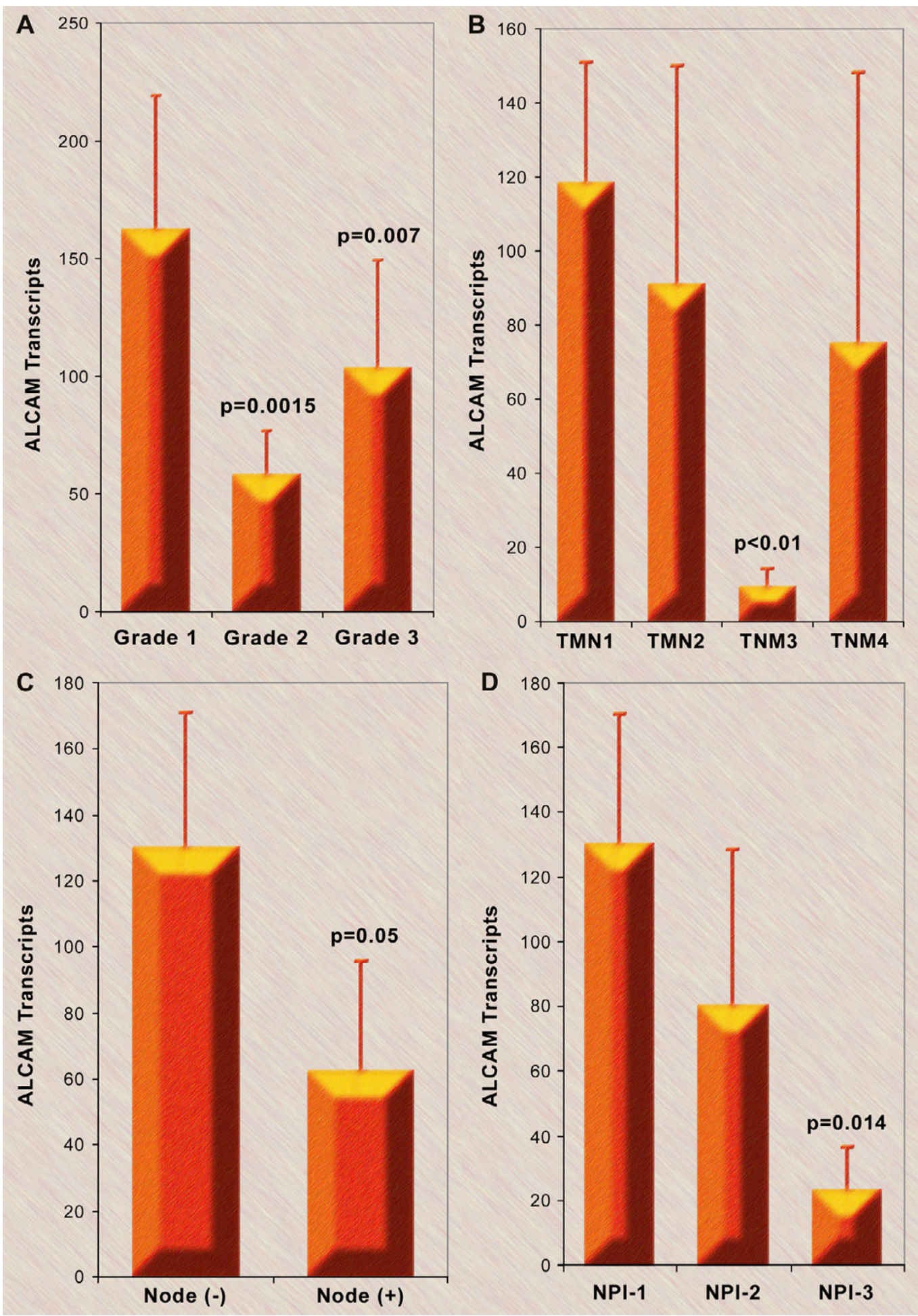

Activated leukocyte cell adhesion molecule (ALCAM) transcript numbers and grade tumor, node, metastasis (TNM) stage, nodal status, and Nottingham Prognostic Index (NPI). (a) The ALCAM transcript number and the grade of tumor. Grade 1 is well differentiated, Grade 2 is moderately differentiated, and Grade 3 is poorly differentiated (mean \pm standard deviation). (b) The ALCAM transcript number and the TNM staging (mean \pm standard deviation). Note that there were only four patients with TNM Stage 4 disease. (c) The ALCAM transcript number and regional nodal status (mean \pm standard deviation). (d) The ALCAM transcript number and NPI. NPI-1 represents the good prognostic group with scores $<3.4, \mathrm{NPI}-2$ represents the moderate prognostic group with scores of 3.4-5.4, and NPI-3 represents the poor prognostic group with scores $>5.4$ (mean \pm standard deviation). 
Figure 5

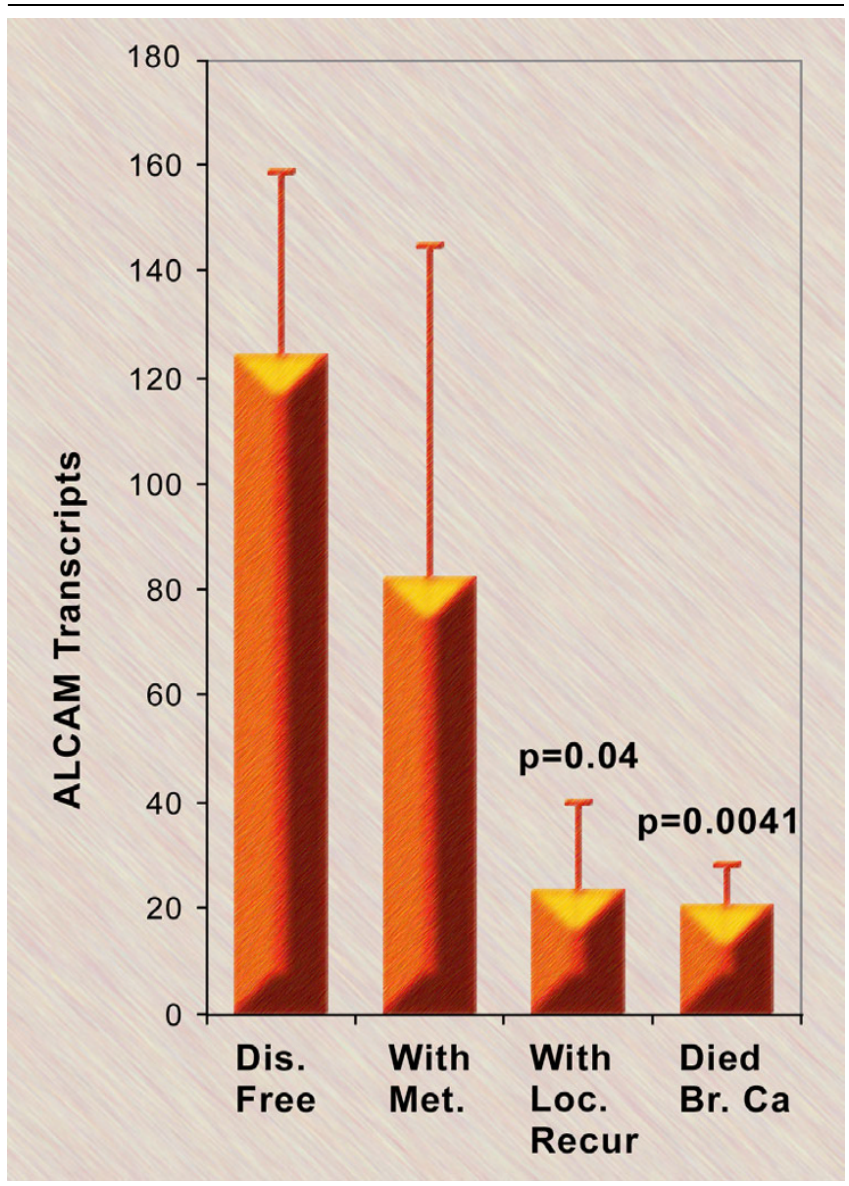

The activated leukocyte cell adhesion molecule (ALCAM) transcript number and clinical outcomes. Patients were divided into disease free (Dis. Free), with metastasis (With Met.), with local recurrence (With Loc. Recur.), or died of breast cancer (Died Br. Ca.) (excluding patients who died of other unrelated diseases) (mean \pm standard deviation).

logic grade into a formula to determine prognostic groups. The group with $\mathrm{NPI}<3.4$ has the best prognosis, NPI $>5.4$ is associated with poor prognosis, and NPI $=3.4-5.4$ has an intermediate prognosis. The scoring system has been validated in prospective studies [40], and is used in countries such as the United Kingdom [41]. Interestingly, the ALCAM transcript number was lower in the worst NPI prognostic group (NPI $>5.4)$ when compared with the best prognostic group (NPI<3.4) $(P=0.014)$ (Fig. 4d).

When patients were divided into categories of disease free, with metastases, with local recurrence, or death due to breast cancer, there was a significant difference in the ALCAM transcript number for those with local recurrence $(P=0.04)$ or those that died of breast cancer $(P=0.0041)$ compared with those that were disease free after excision of primary tumor (Fig. 5). Altogether, the present data
Figure 6

\section{Survival Functions}

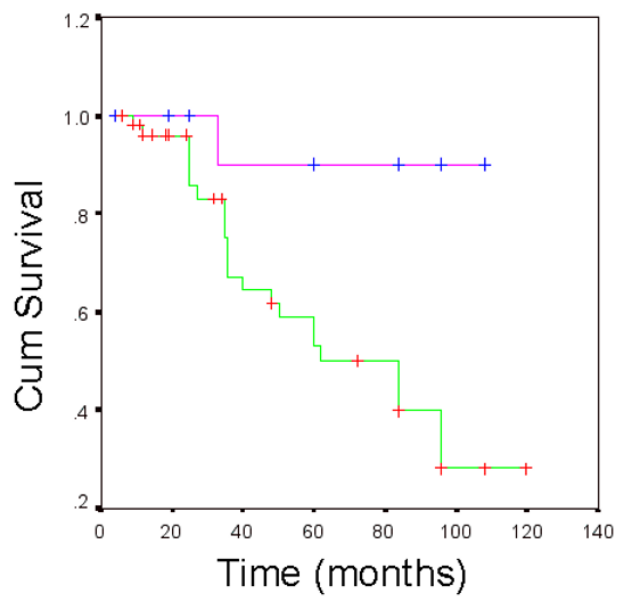

Kaplan-Meier incident curve including metastasis, recurrence, and death (all but disease free). Patients were divided into two groups based on the level of transcripts of activated leukocyte cell adhesion molecule (ALCAM). Pink line, patients with high levels of ALCAM; green line, patients with low levels of ALCAM. Pink line, mean time to incident was 100.5 months. Green line, mean time to incident was 79.6 months. Cox proportion analysis between the two groups, $P=0.009$.

strongly suggest that a lower ALCAM transcript number in the primary tumor is associated with a worse prognosis. This is confirmed in the Kaplan-Meier survival curve (Fig. 6), which shows that patients with low levels of ALCAM have more incidents of metastasis, recurrence, or death when compared with patients with high levels of ALCAM RNA in the primary tumor.

Only two types of cancer have been previously evaluated for ALCAM - melanoma and prostate cancer. With melanoma there was increased staining for ALCAM during the vertical growth phase of the tumor [17]. This would suggest that ALCAM is involved in tumor growth and progression. ALCAM expression was decreased in high-grade prostate carcinoma, suggesting that altered expression correlated with tumor grade [18]. Notably, in breast cancer there does appear to be distinct differences in ALCAM transcript levels in patients that correspond to prognosis. We hypothesize that altered expression of ALCAM may be related to tumor proliferation, adhesion, and metastatic capability. During the 6-year follow-up of the patients used in the present study, decreased ALCAM transcripts in the primary tumors correlated with nodal involvement, higher grade tumors, higher TNM stage, worse NPI index, presence of local recurrence, and death due to breast cancer. Clearly the data suggest that decreased ALCAM expression in the primary tumor is of clinical significance in breast cancer, and that reduced expression indicates a more aggressive phenotype and poor prognosis. 
We hypothesize that the reduced expression of ALCAM, a molecule involved in cell adhesion, may allow the tumor cells to disaggregate, allowing cells to enter the circulation and metastasize, a phenomenon mirrored by other cell adhesion molecules such as E-cadherin [35-38]. ALCAM is known to colocalize with E-cadherin in epithelial cells [42]. With E-cadherin, a number of mechanisms operate for its reduction in cancer cells, including shedding of the cadherin extracellular domain, redistribution from the cell surface to the cytoplasm or from cell-cell adhesion areas to other areas of the membrane, and transcriptional abnormalities as a result of gene promoter hypermethylation [38]. The current study has shown that both cytoplasmic staining and membranous staining of ALCAM are lower in cancer cells, strongly arguing the possibility of transcriptional aberration. It would be important to examine such events as promoter methylation in the future.

The present study suggests that although there is no significant difference between normal breast tissue and breast cancer in ALCAM transcript number (Fig. 3a), and immunohistochemistry alone does not distinguish between benign and malignant cells in the breast, PCR can be used to identify more aggressive tumors.

\section{Conclusions}

ALCAM is a glycoprotein that is involved with cellular adhesion, proliferation, and tumor progression. In breast carcinoma, decreased ALCAM transcripts in the primary tumors correlate with nodal involvement, higher grade tumors, higher TNM stage, worse NPI index, the presence of local recurrence, and death due to breast cancer. This study suggests that the level of ALCAM expression in primary breast carcinoma has clinical significance, and that reduced expression indicates a more aggressive phenotype and poor prognosis.

\section{Competing interests}

None declared.

\section{Acknowledgements}

The authors thank Gareth Watkins and Sandra Chapman for immunohistochemical staining of tissues, and Adrian Hoff for assistance with micrographs. WGJ's work was supported by the Breast Cancer Campaign (UK).

\section{References}

1. American Cancer Society: Cancer Facts \& Figures 2004. Atlanta, GA 2004.

2. Breast. In AJCC Cancer Staging Manual fifth edition. Edited by: Fleming I, Cooper J, Henson D, Hutter R, Kennedy B, Murphy G, O'Sullivan B, Sobin L, Yarbro J. Philadelphia: Lippincott-Raven; 1997:171-178.

3. Pourquie O, Corbel C, Le Caer J-P, Rossier J, Le Douarin N: BEN, a surface glycoprotein of the immunoglobulin superfamily, is expressed in a variety of developing systems. Proc Natl Acad Sci USA 1992, 89:5261-5265.

4. Tanaka H, Matsui T, Agata A, Tomura M, Kubota I, McFarland KC, Kohr B, Lee A, Phillips HS, Shelton DL: Molecular cloning and expression of a novel adhesion molecule, SC1. Neuron 1991, 7:535-545.

5. Burns F, von Kannen S, Guy L, Raper J, Kamholz J, Chang S: DMGRASP, a novel immunoglobulin superfamily axonal surface protein that supports neurite extension. Neuron 1991 7:209-220.

6. Peduzzi J, Irwin M, Geisert E: Distribution and characteristics of a $90 \mathrm{kDa}$ protein, KG-CAM in the rat CNS. Brain Res 1994 640:296-307.

7. Paschke K, Lottspeich F, Stuermer C: Neurolin, a cell surface glycoprotein on growing retinal axons in the goldfish visual systems, is reexpressed during retinal axonal regeneration. $J$ Cell Biol 1992, 117:863-875.

8. Degen W, van Kempen L, Gijzen E, van Groningen J, van Kooyk Y, Bloemers $\mathrm{H}, \mathrm{Swart} \mathrm{G}$ : MEMD, a new cell adhesion molecule in metastasizing human melanoma cell lines, is identical to ALCAM (activated leukocyte cell adhesion molecule). Am J Pathol 1998, 152:805-813.

9. Bowen MA, DD Patel, Li X, Modrell B, Malacko AR, Wang W-C, Marquardt H, Neubauer M, Pesando JM, Francke U, Haynes BF, Aruffo A: Cloning, mapping, and characterization of activated leukocyte-cell adhesion molecule (ALCAM), a CD6 ligand. $J$ Exp Med 1995, 181:2213-2220.

10. Bowen MA, Bajorath J, D'Egidio M, Whitney GS, Palmer D, Kobarg J, Starling GC, Siadak AW, Aruffo A: Characterization of mouse ALCAM (CD166): the CD6-binding domain is conserved in different homologs and mediates cross-species binding. Eur $J$ Immunol 1997, 27:1469-1478.

11. Kurata $H$, Matsumoto $A$, Fujiwara $Y$, Kondo $K$, Itakura $H$, Mitchell $A$, Fidge $\mathrm{N}$ : A candidate high density lipoprotein (HDL) receptor, $\mathrm{HB}_{2}$, with possible multiple functions shows sequence homology with adhesion molecules. J Atheroscler Thromb 1998 , 4:112-117.

12. Matsumoto $A$, Mitchell $A$, Kurata $H$, Pyle L, Kondo $K$, Itakura $H$, Fidge $\mathrm{N}$ : Cloning and characterization of $\mathrm{HB}_{2}$, a candidate high density lipoprotein receptor. Sequence homology with members of the immunoglobulin superfamily of membrane proteins. J Biol Chem 1997, 272:16778-16782.

13. Swart GWM: Activated leukocyte cell adhesion molecule (CD 166/ALCAM): developmental and mechanistic aspects of cell clustering and cell migration. Eur J Cell Bio/ 2002, 81:313-321.

14. van Kempen LCLT, Nelissen JMDT, Degen WGJ, Torensma R, Weidle UH, Bloemers HPJ, Figdor CF, Swart GWM: Molecular basis for the homophilic activated leukocyte cell adhesion molecule (ALCAM)-ALCAM interaction. J Biol Chem 2001, 276:25783-25790.

15. Ohneda O, Ohneda K, Arai $F$, Lee J, Miyamoto T, Fukushima $Y$, Dowbenko D, Lasky LA, Suda T: ALCAM (CD166): its role in hematopoietic and endothelial development. Blood 2001, 98:2134-2142.

16. Arai F, Ohneda O, Miyamoto T, Zhang X, Suda T: Mesenchymal stem cells in perichondrium express activated leukocyte cell adhesion molecule and participate in bone marrow formation. $J$ Exp Med 2002, 195:1549-1563.

17. van Kempen LCLT, van den Oord JJ, van Muijen GNP, Weidle UH, Bloemers HPJ, Swart GWM: Activated leukocyte cell adhesion molecule/CD166, a marker of tumor progression in primary malignant melanoma of the skin. Am J Pathol 2000, 156:769-774.

18. Kristiansen G, Pilarsky C, Wissmann C, Stephan C, Weissbach L, Loy V, Loening S, Dietel M, Rosenthal A: ALCAM/CD166 is upregulated in low-grade prostate cancer and progressively lost in high-grade lesions. The Prostate 2003, 54:34-43.

19. King JA, Al-Mehdi A-B, Ofori-Acquah SF, Stevens T: Role of ALCAM in interaction of breast cancer metastases and the endothelium of the lung [abstract]. FASEB J 2004, 18:A330.

20. Jiang WG, Douglas-Jones A, Mansel RE: Level of expression of lipoxygenases and cyclooxygenase-2 in human breast cancer. Prostaglandins Leukot Essent Fatty Acids 2003, 69:275-281.

21. Jiang WG, Douglas-Jones A, Mansel RE: Expression of peroxisome-proliferator activated receptor-gamma (PPAR $\gamma$ ) and the PPARgamma co-activator, PGC-1 in human breast cancer correlates with clinical outcomes. Int J Cancer 2003, 106:752-757.

22. Jiang WG, Watkins G, Lane J, Cunnick GH, Douglas-Jones $A$ Mokbel K, Mansel RE: Prognostic value of Rho GTPases and Rho guanine nucleotide dissociation inhibitors in human breast cancers. Clin Cancer Res 2003, 9:6432-6440. 
23. Parr C, Watkins G, Mansel RE, Jiang WG: The hepatocyte growth factor regulatory factors in human breast cancer. Clin Cancer Res 2004, 10:202-211.

24. Al-Rawi MA, Rmali K, Watkins G, Mansel RE, Jiang WG: Aberrant expression of interleukin-7 (IL-7) and its signaling complex in human breast cancer. Eur J Cancer 2004, 40:494-502.

25. Davies G, Cunnick GH, Mansel RE, Mason MD, Jiang WG: Levels of expression of endothelial markers specific to tumour-associated endothelial cells and their correlation with prognosis in patients with breast cancer. Clin Exp Metastasis 2004, 21:31-37.

26. Nazarenko IA, Bhatnagar SK, Hohman RJ: A closed tube format for amplification and detection of DNA based on energy transfer. Nucleic Acids Res 1997, 25:2516-2521.

27. Somlyo AV, Bradshaw D, Ramos S, Murphy C, Myers CE, Somlyo AP: Rho-kinase inhibitor retards migration and in vivo dissemination of human prostate cancer cells. Biochem Biophy Res Commun 2000, 269:652-659.

28. Cunnick GH, Jiang WG, Gomez KF, Mansel RE: Lymphangiogenesis quantification using quantitative PCR and breast cancer as a model. Biochem Biophys Res Commun 2001, 288:1043-1046.

29. Davies G, Jiang WG, Mason MD: Cell-cell adhesion molecules and signaling intermediates and their role in the invasive potential of prostate cancer cells. J Urol 2000, 163:985-992.

30. Kuniyasu $H$, Ellis LM, Evans DB, Abbruzzese JL, Fenoglio CJ, Bucana CD, Cleary KR, Tahara E, Fidler IJ: Relative expression of E-cadherin and type IV collagenase genes predicts disease outcome in patients with resectable pancreatic carcinoma. Clin Cancer Res 1999, 5:25-33.

31. Uchida N, Yang Z, Combs J, Pourquie O, Nguyen M, Ramanathan R, Fu J, Welply A, Chen S, Weddell G, Sharma AK, Leiby KR, Karagogeos D, Hill B, Humeau L, Stallcup WB, Hoffman R, Tsukamoto AS, Gearing DP, Peault B: The characterization, molecular cloning, and expression of a novel hematopoietic cell antigen from $\mathrm{CD} 34^{+}$human bone marrow cells. Blood 1997, 89:2706-2716.

32. Stephan J-P, Bald L, Roberts PE, Lee J, Gu Q, Mather JP: Distribution and function of the adhesion molecule BEN during rat development. Dev Biol 1999, 212:264-277.

33. Corbel C, Bluestein HG, Pourquie O, Vaigot P, Le Douarin NM: An antigen expressed by avian neuronal cells is also expressed by activated T lymphocytes. Cell Immunol 1992, 141:99-110.

34. Corbel C, Pourquie O, Cormier F, Vaigot $P$, Le Douarin NM: BEN/ SC1/DM-GRASP, a homophilic adhesion molecule, is required for in vitro myeloid colony formation by avian hemopoietic progenitors. Proc Natl Acad Sci USA 1996, 93:2844-2849.

35. Moll R, Mitze M, Frixen UH, Birchmeier W: Differential loss of Ecadherin expression in infiltrating ductal and lobular breast carcinomas. Am J Pathol 1993, 143:1731-1742.

36. Goldstein NS, Bassi D, Watts JC, Layfield L, Yaziji H, Gown AM: E-cadherin reactivity of 95 noninvasive ductal and lobular lesions of the breast. Implications for the interpretation of problematic lesions. Am J Clin Pathol 2001, 115:534-542.

37. Acs G, Lawton TJ, Rebbeck TR, LiVolsi VA, Zhang PJ: Differential expression of E-cadherin in lobular and ductal neoplasms of the breast and its biologic and diagnostic implications. $A m ~ J$ Clin Pathol 2001, 115:85-98.

38. Jiang WG: E-cadherin and its associated protein catenins, cancer invasion and metastasis. Br J Surg 1996, 83:437-446.

39. Ellis I, Pinder S, Lee A, Elston C: Tumors of the breast. In Diagnostic Histopathology of Tumors second edition. Edited by: Fletcher C. New York: Churchill Livingstone; 2000:865-930.

40. Galea MH, Blamey RW, Elston CE, Ellis IO: The Nottingham Prognostic Index in primary breast cancer. Breast Cancer Res Treat 1992, 22:207-219.

41. Miller W, Ellis I, Sainsbury J, Dixon J: ABC of breast diseases. Prognostic factors. Br J Med 1994, 309:1573-1576.

42. Tomita K, van Bokhoven A, Jansen CFJ, Bussemakers MJG, Schalken JA: Coordinate recruitment of E-cadherin and ALCAM to cell-cell contacts by a-catenin. Biochem Biophy Res Commun 2000, 267:870-874. 